\section{BMJ Open Respiratory Research}

\title{
Sudden death in individuals with obstructive sleep apnoea: a systematic review and meta-analysis
}

\author{
Emily S Heilbrunn, ${ }^{1}$ Paddy Ssentongo, ${ }^{1,2}$ Vernon M Chinchilli, ${ }^{1}$ John Oh, ${ }^{3}$ \\ Anna E Ssentongo (D) ${ }^{1,3}$
}

To cite: Heilbrunn ES, Ssentongo P, Chinchilli VM, et al. Sudden death in individuals with obstructive sleep apnoea: a systematic review and meta-analysis. BMJ Open Resp Res 2021;8:e000656. doi:10.1136/ bmjresp-2020-000656

- Additional supplemental material is published online only. To view, please visit the journal online (http://dx.doi. org/10.1136/bmjresp-2020000656).

ESH and PS contributed equally.

Received 2 June 2020 Accepted 2 May 2021

Check for updates

(C) Author(s) (or their employer(s)) 2021. Re-use permitted under CC BY-NC. No commercial re-use. See rights and permissions. Published by BMJ.

${ }^{1}$ Public Health Sciences, Penn State Health Milton S Hershey Medical Center, Hershey,

Pennsylvania, USA

${ }^{2}$ Center for Neural

Engineering, Penn State University, University Park, Pennsylvania, USA

${ }^{3}$ Department Surgery, Penn

State Health Milton S Hershey

Medical Center, Hershey,

Pennsylvania, USA

Correspondence to

Anna E Ssentongo;

assentongo@pennstatehealth. psu.edu

\section{ABSTRACT}

Objectives Over 1 billion individuals worldwide experience some form of sleep apnoea, and this number is steadily rising. Obstructive sleep apnoea (OSA) can negatively influence one's quality of life and potentially increase mortality risk. However, the association between OSA and mortality has not been reliably estimated. This metaanalysis estimates the risk of all-cause and cardiovascular mortality in individuals with OSA.

Design Systematic review and meta-analysis.

Data sources MEDLINE, Cochrane Library, Scopus and Joanna Briggs Institute Evidence-Based Practice databases were searched from inception through 1 January 2020. Eligibility criteria for selecting studies We included observational studies assessing the association of sudden deaths in individuals with and without OSA.

Data extraction and synthesis Two independent reviewers (AES and ESH) extracted data and assessed the risk of bias using the Newcastle-Ottawa Scale quality assessment tool. Data were pooled using the randomeffects models and reported as risk ratios (RRs) with 95\% Cls. Heterogeneity was quantified with $\mathrm{I}^{2}$ statistic.

Results We identified 22 observational studies ( $n=42099$ participants). The mean age was 62 years and $64 \%$ were men. OSA was associated with all-cause sudden death ( $\mathrm{RR}=1.74,95 \% \mathrm{Cl}: 1.44$ to $2.10, \mathrm{I}^{2}=72 \%$ ) and cardiovascular mortality ( $\mathrm{RR}=1.94,95 \% \mathrm{Cl}: 1.39$ to $2.70, I^{2}=32 \%$ ). A marginally significant dose-response relationship between severity of OSA and the risk of death was observed ( $p$ for interaction $=0.05)$ : mild OSA $(R R=1.16$, $95 \% \mathrm{Cl}: 0.70$ to 1.93), moderate 0SA ( $\mathrm{RR}=1.72,95 \% \mathrm{Cl}$ : 1.11 to 2.67 ) and severe OSA ( $R R=2.87,95 \% \mathrm{Cl}: 1.70$ to 4.85). Meta-regression analysis showed that older age was a significant contributing factor in the relationship between OSA and mortality. The median study methodological quality was considered high.

Conclusions OSA is a significant risk factor for all-cause mortality and cardiac mortality. Prevention and treatment strategies to optimise survival and quality of life in individuals with OSA are urgently needed. PROSPERO registration number CRD42020164941.

\section{INTRODUCTION}

Obstructive sleep apnoea (OSA) is a chronic sleep disorder in which individuals experience complete or partial obstruction of the upper airway structures, ${ }^{12}$ with a resultant reduction

\section{Key messages}

Are individuals with sleep apnoea at an increased risk for cardiovascularand all-cause sudden death?

- Sleep apnoea is associated with an increased risk of cardiovascular mortality and all-cause sudden death, with a marginally significant dose-response relationship, where those with severe sleep apnoea are at the highest risk of mortality.

- The present systematic review and meta-analysis synthesise and quantify the risk of mortality in individuals with sleep apnoea, highlighting important directions for future research that focuses on the prevention of obstructive sleep apnoea.

or complete blockage of airflow during sleep, intermittent hypoxia and sleep disturbances. ${ }^{3}$ Common symptoms of OSA, such as excessive daytime sleepiness, fatigue, heavy snoring and non-refreshing sleep, have the potential to play an influential role in one's quality of life (QOL). ${ }^{4}$ OSA also increases one's risk of developing several cardiovascular-related comorbidities, including heart failure, arrhythmias and coronary artery disease. ${ }^{5}$ Individuals with an apnoea-hypopnoea index (AHI) $>36$ have a threefold higher risk of all-cause mortality in comparison to other $\mathrm{AHI}$ scores $(\mathrm{HR}=3.30$; $95 \%$ CI 1.74 to 6.26$).{ }^{6}$ Patients with OSA who are classified as moderate (AHI 15-30) to severe (AHI >30) have an increased risk of many adverse outcomes, specifically allcause mortality. ${ }^{7}$ As a result of this, the risk of mortality in patients diagnosed with OSA has become a growing and pervasive concern.

OSA is a growing public health concern, with previous studies in the literature reporting an increasing global prevalence of upwards of 1 billion individuals. ${ }^{8}$ Estimates within the USA suggest that approximately $15 \%$ of adults are clinically diagnosed with OSA. ${ }^{9}$ A large portion of the population suffers from OSA-like symptoms without receiving any diagnosis or treatment. This 
group continues to further the burden placed on the public health and medical systems. Identifying individuals diagnosed with OSA who are considered at-risk for adverse health outcomes can reduce the economic cost and burden on the healthcare system. ${ }^{10}$

Existing evidence on the association between OSA and the risk of sudden death is insufficient and inconclusive. Our objective is to estimate the association of OSA and the mortality risk. We hypothesise that OSA is a risk factor for cardiac events and all-cause mortality. The present systematic review and meta-analysis estimate the risk of all-cause and cardiovascular mortality in individuals with OSA.

\section{METHODS}

Search strategy and selection criteria

Design

We registered the present study with PROSPERO and the study protocol has been published. ${ }^{11}$ The findings are reported according to the guidelines of the of the Meta-analyses Of Observational Studies in Epidemiology checklist (online supplemental table 1).

\section{Data source and searches}

We searched MEDLINE, Cochrane Library, Scopus and Joanna Briggs Institute Evidence-Based Practice databases from inception through 1 January 2020. Full search terms

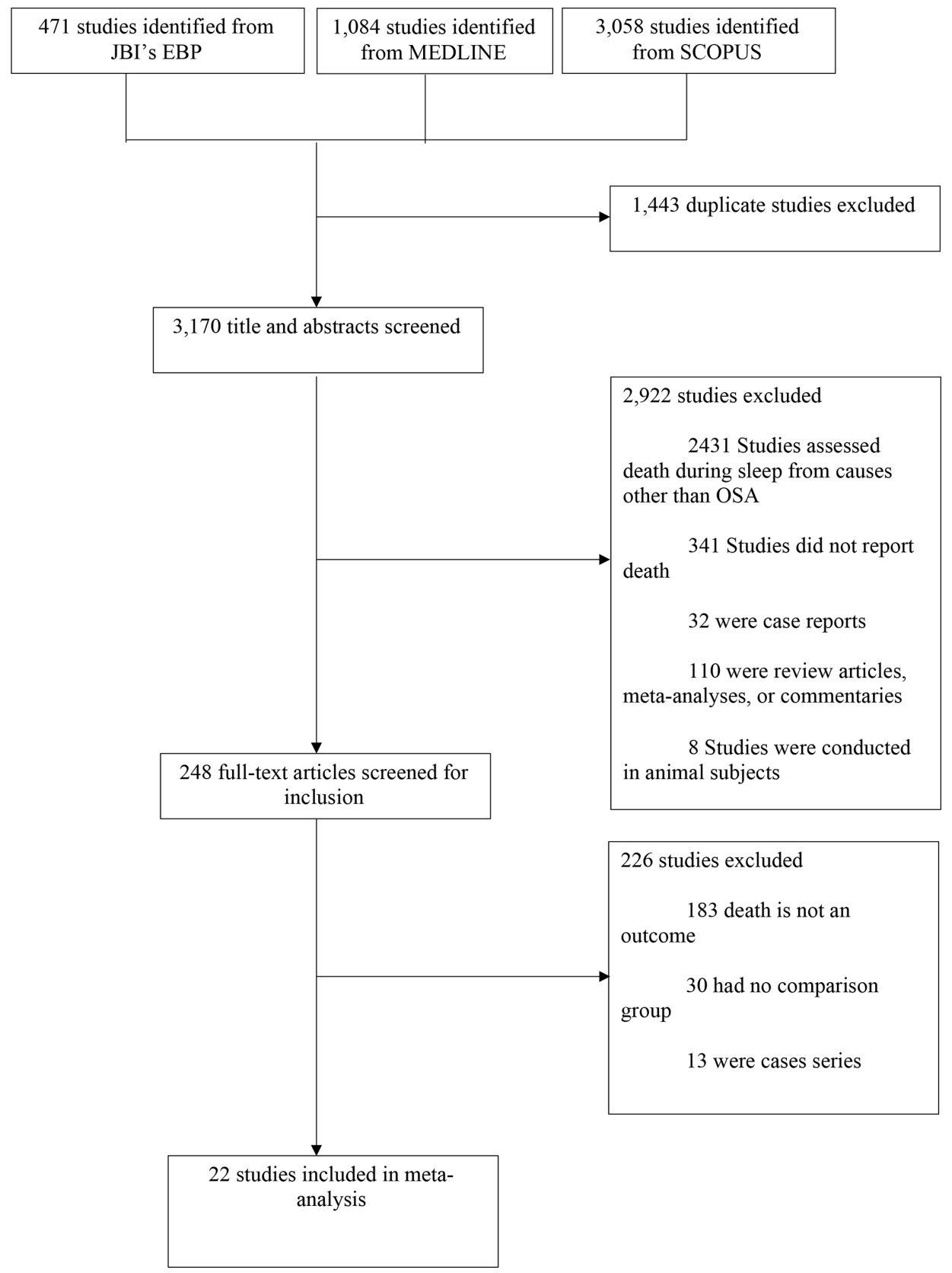

Figure 1 Preferred Reporting Items for Systematic Reviews and Meta-Analyses flow diagram. JBI, Joanna Briggs Institute; OSA, obstructive sleep apnoea;EBP, Evidence-Based Practice. 


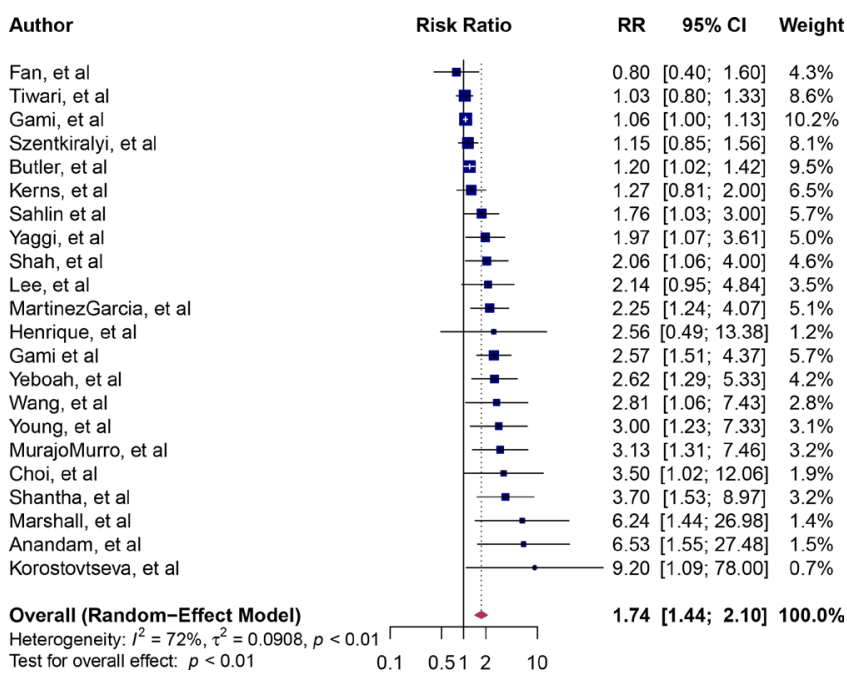

Figure 2 Forest plot of pooled risk ratio for the association of OSA with all-cause sudden death. Blue squares and their corresponding lines are the point estimates and $95 \% \mathrm{Cl}$. Maroon diamonds represent the pooled estimate (width denotes $95 \% \mathrm{Cl}$ ). Heterogeneity was considered high $\left(I^{2}=72 \%\right)$. OSA, obstructive sleep apnoea.

used in this study are presented in online supplemental table 2. In summary, search terms included Medical Subject Headings with combinations of 'sleep apnoea, obstructive' and 'death, sudden and 'cardiac death". We screened reference lists of identified articles for potential eligibility as well. We did not impose any limitations related to the date of publication, language or geographical location.

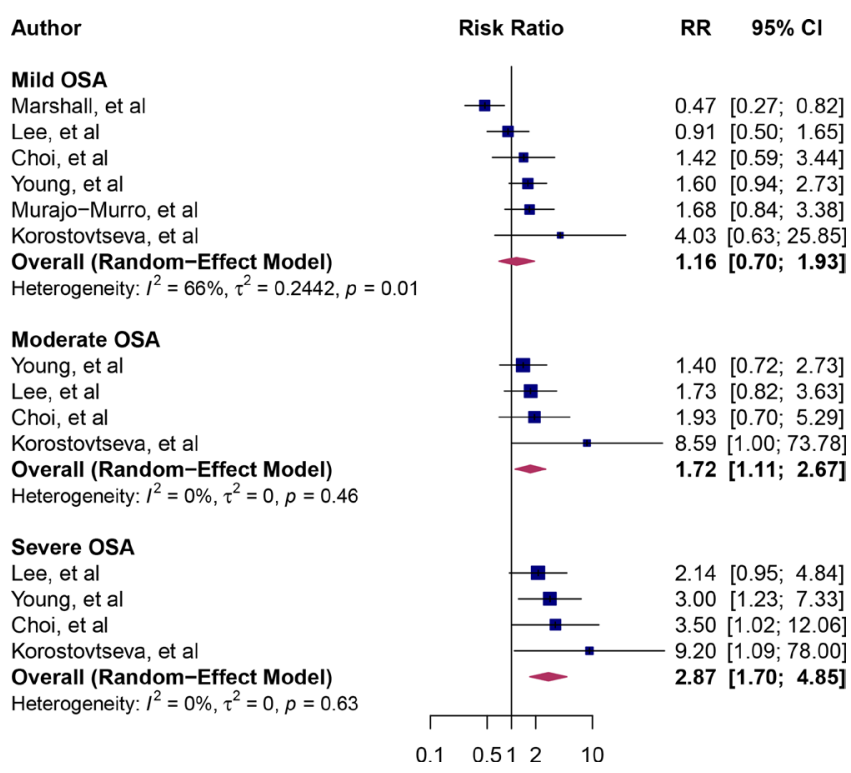

Figure 3 Forest plot of subgroup analysis by the severity of OSA. Blue squares and their corresponding lines are the point estimates and $95 \% \mathrm{Cl}$. Maroon diamonds represent the pooled estimate for each subgroup (width denotes $95 \% \mathrm{Cl})$. Heterogeneity by severity of OSA: mild $\left(I^{2}=66 \%\right)$; moderate $\left(I^{2}=0 \%\right)$; severe $\left(I^{2}=0 \%\right)$; $p$ for interaction comparing the different subgroups $=0.05$. OSA, obstructive sleep apnoea.

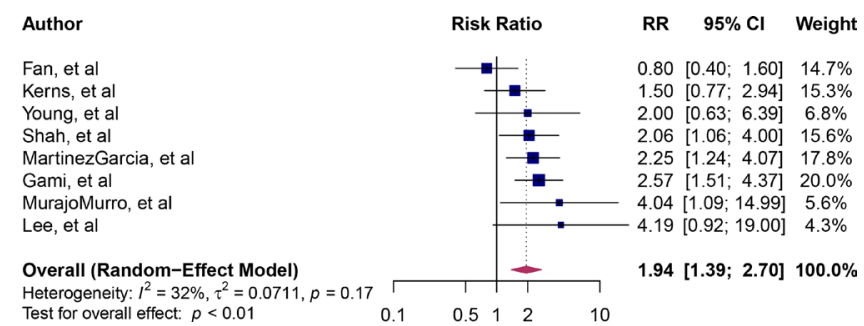

Figure 4 Forest plot of pooled risk ratio for the association of OSA and cardiovascular mortality. Blue squares and their corresponding lines are the point estimates and $95 \% \mathrm{Cl}$. Maroon diamonds represent the pooled estimate for each subgroup (width denotes $95 \% \mathrm{Cl}$ ). OSA, obstructive sleep apnoea.

\section{Study selection}

We included observational studies that reported rates of sudden death in individuals with OSA. Studies that reported the rates of sudden death in both patients with and without OSA were included. The exclusion criteria were: (1) studies not conducted on humans and did not report the estimates of the outcome of interest or, (2) did not provide enough information to calculate them, (3) review papers, (4) meta-analyses, (5) literature reviews, (6) commentaries and (7) conference abstracts.

\begin{tabular}{|c|c|c|c|c|}
\hline Author & Risk Ratio & RR & $95 \% \mathrm{Cl}$ & Weight \\
\hline \multicolumn{5}{|l|}{ High quality score } \\
\hline Tiwari, et al & 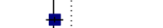 & 1.03 & {$[0.80 ; 1.33]$} & $8.6 \%$ \\
\hline Szentkiralyi, et al & E & 1.15 & {$[0.85 ; 1.56]$} & $8.1 \%$ \\
\hline Butler, et al & I & 1.20 & {$[1.02 ; 1.42]$} & $9.5 \%$ \\
\hline Kerns, et al & - & 1.27 & {$[0.81 ; 2.00]$} & $6.5 \%$ \\
\hline Sahlin et al & $\rightarrow$ & 1.76 & {$[1.03 ; 3.00]$} & $5.7 \%$ \\
\hline Lee, et al & 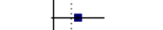 & 2.14 & {$[0.95 ; 4.84]$} & $3.5 \%$ \\
\hline MartinezGarcia, et al & & 2.25 & {$[1.24 ; 4.07]$} & $5.1 \%$ \\
\hline Henrique, et al & . & 2.56 & {$[0.49 ; 13.38]$} & $1.2 \%$ \\
\hline Yeboah, et al & 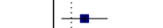 & 2.62 & {$[1.29 ; 5.33]$} & $4.2 \%$ \\
\hline Wang, et al & - & 2.81 & {$[1.06 ; 7.43]$} & $2.8 \%$ \\
\hline Young, et al & 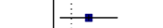 & 3.00 & {$[1.23 ; 7.33]$} & $3.1 \%$ \\
\hline MurajoMurro, et al & $\rightarrow-$ & 3.13 & {$[1.31 ; 7.46]$} & $3.2 \%$ \\
\hline Choi, et al & $\rightarrow$ & 3.50 & {$[1.02 ; 12.06]$} & $1.9 \%$ \\
\hline Shantha, et al & $=$ & 3.70 & {$[1.53 ; 8.97]$} & $3.2 \%$ \\
\hline Marshall, et al & 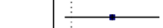 & 6.24 & {$[1.44 ; 26.98]$} & $1.4 \%$ \\
\hline Anandam, et al & $\rightarrow$ & 6.53 & {$[1.55 ; 27.48]$} & $1.5 \%$ \\
\hline Korostovtseva, et al & & 9.20 & {$[1.09 ; 78.00]$} & $0.7 \%$ \\
\hline $\begin{array}{l}\text { Overall (Random-Effect Model) } \\
\text { Heterogeneity: } I^{2}=64 \%, \tau^{2}=0.1163, p<0.01\end{array}$ & - & 1.91 & {$[1.50 ; 2.44]$} & $70.3 \%$ \\
\hline \multicolumn{5}{|l|}{ Moderate quality score } \\
\hline Fan, et & - & 0.80 & {$[0.40 ; 1.60]$} & $4.3 \%$ \\
\hline Gami, et al & $\phi$ & 1.06 & {$[1.00 ; 1.13]$} & $10.2 \%$ \\
\hline Yaggi, et al & - & 1.97 & {$[1.07 ; 3.61]$} & $5.0 \%$ \\
\hline Shah, et al & - & 2.06 & {$[1.06 ; 4.00]$} & $4.6 \%$ \\
\hline Gami et al & - & 2.57 & {$[1.51 ; 4.37]$} & $5.7 \%$ \\
\hline $\begin{array}{l}\text { Overall (Random-Effect Model) } \\
\text { Heterogeneity: } I^{2}=79 \%, \tau^{2}=0.1851, p<0.01\end{array}$ & - & 1.52 & {$[0.97 ; 2.37]$} & $29.7 \%$ \\
\hline Over & $\vdots$ & 1.74 & {$[1.44 ; 2.10]$} & $100.0 \%$ \\
\hline Heterogeneity: $I^{2}=72 \%, \tau^{2}=0.0908, p<0.01$ & T & & & \\
\hline $\begin{array}{l}\text { Residual heterogeneity: } I^{2}=68 \%, p<0.01 \quad 0.1 \\
\text { Test for overall effect: } p<0.01\end{array}$ & 0.512 & & & \\
\hline
\end{tabular}

Figure 5 Forest plot of subgroup analysis by study quality score. Blue squares and their corresponding lines are the point estimates and $95 \% \mathrm{Cl}$. Maroon diamonds represent the pooled estimate for each subgroup (width denotes $95 \% \mathrm{Cl}$ ). Heterogeneity by methodological quality score: high quality score $\left(I^{2}=64 \%\right)$; moderate quality score $\left(I^{2}=79 \%\right) ; p$ for interaction comparing the different subgroups $=0.37$. 


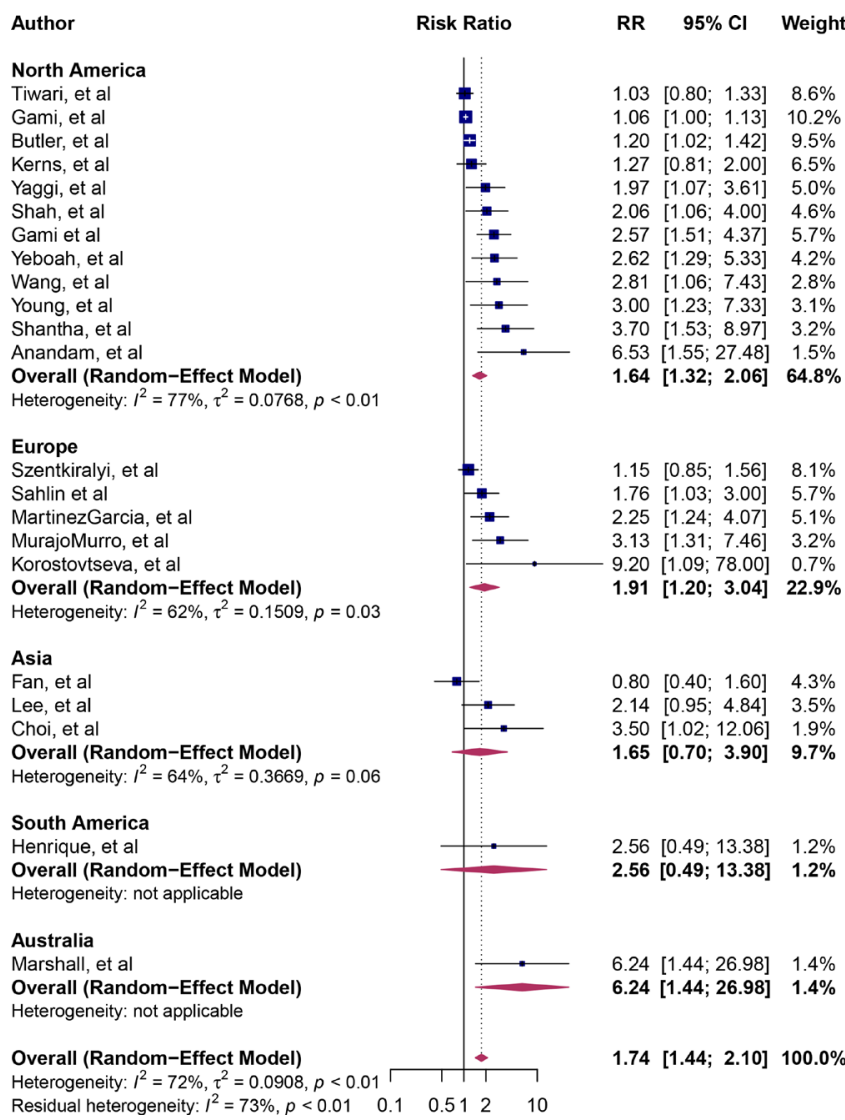

Figure 6 Forest plot for subgroup analysis by the continent of the study population. Blue squares and their corresponding lines are the point estimates and $95 \% \mathrm{Cl}$. Maroon diamonds represent the pooled estimate for each subgroup (width denotes $95 \% \mathrm{Cl}$ ). Heterogeneity by continent: North America $\left(I^{2}=77 \%\right)$; Europe $\left(1^{2}=62 \%\right)$; Asia $\left(I^{2}=64 \%\right)$; South America $\left(I^{2}\right.$ not applicable); Australia $\left(I^{2}=\right.$ not applicable); $p$ for interaction comparing the different subgroups $=0.47$.

\section{Data extraction}

Two authors (ESH and AES) screened titles and abstracts of the studies for inclusion eligibility independently. After screening initial articles, ESH and AES manually screened full-text articles for continued inclusion criteria. Disagreements were settled by another author (PS). Relevant data from each report were extracted and this included first author, year of publication, country of publication, number of participants with and without OSA, the median age of participants in both study groups, the median body mass index of participants with and without OSA, the proportion of the sample that was men, the proportion of the study sample who smoked, the proportion of the study sample with hypertension and diabetes, the number of participants with OSA who died, the number of participants without OSA who died, the number of participants who did not die from both groups, risk ratios (RRs) of sudden death and their corresponding $95 \%$ CI. Priority was given to adjusted estimates.
Study quality assessment and categorisation

Study methodological quality was assessed independently by the two reviewers (ESH, AES) using the NewcastleOttawa Scale quality assessment tool. Three parameters were used for rating observational studies: selection, comparability between exposed and unexposed groups, and exposure/outcome assessment. Studies with less than 5 stars of quality were given a low rating, those with 5-7 were given moderate quality and greater than 7 was considered high. The risk of bias for each included trial was assessed independently.

\section{Statistical analyses}

We summarised the study selection process, the sample size and the sociodemographic characteristics of each study, including sex, mean/median age and the number of variables adjusted. The primary outcome was the risk of all-cause sudden mortality in individuals with OSA compared with individuals without OSA.

Cardiovascular mortality associated with OSA was the secondary outcome of interest. To calculate the pooled effect estimate and the $95 \%$ CIs, random-effects models with a generic inverse-variance method were fitted with the metagen function from the $\mathrm{R}$ package meta. ${ }^{12}$ DerSimonian and Laird method was used to calculate the between-study variance. ${ }^{13}$ We used the reported RR estimates ( $R R, H R, O R$ ) as measures of the association between OSA and the risk of mortality. If an outcome is rare in all populations and subgroups, the distinctions among different measures of RRs (eg, ORs, rate ratios and RRs) can be ignored, ${ }^{14}$ thus we combined RRs and HRs with ORs in the present metaanalysis and reported the pooled effect size as RRs as common risk estimates for all studies.

We quantified between-study variation using $\mathrm{I}^{2}$ statistics, expressed as \% (low (25\%), moderate $(50 \%)$ and high $(75 \%)) .{ }^{15}{ }^{16}$ Influence sensitivity analysis (leave-out-one method) was conducted to estimate the influence of individual study on the overall pooled RR. ${ }^{17}$ Potential sources of heterogeneity were explored with subgroup and meta-regression analyses. Mean or median age, continent, publication year, the proportion of individuals with diabetes and gender were used as covariates. ${ }^{18}$ Funnel plots and Egger's test were conducted to explore publication and small study bias. ${ }^{19}$ Finally, possible publication bias was adjusted using trim and fill analyses using Duval and Tweedie's non-parametric method. ${ }^{20} \mathrm{R}$ software, V.3.4.3 (R Core Team, Vienna, Austria) was used to conduct the analyses. ${ }^{21}$

\section{RESULTS}

\section{Overview}

Figure 1 shows the study selection process. We identified 4613 reports of which 22 met eligibility criteria. ${ }^{6} 722-47$ Of the studies, 12 studies were from North America, 5 from Europe, 3 from Asia and 1 from South America and Australia each. A total of 42099 individuals were 


\begin{tabular}{lllll}
\hline Table 1 & Results of meta-regression analysis. & & & \\
\hline Exposure & Covariate & N studies & Coefficient $(95 \%$ Cl $)$ & P value \\
\hline OSA & \% Male & 22 & $-0.007(-0.02$ to 0.02$)$ & 0.94 \\
OSA & Age & 11 & $0.04(0.01$ to 0.07$)$ & 0.003 \\
OSA & Publication year & 22 & $-0.05(-0.09$ to -0.009$)$ & 0.017 \\
OSA & \% Diabetes & 9 & $0.005(-0.004$ to 0.001$)$ & 0.31 \\
\hline
\end{tabular}

Age and publication year were significant explanatory variables for the variation in the risk of mortality associated with OSA.

*Age was the mean age of study population; otherwise, the median age was used. Publication year is per increasing year of publication.

OSA, obstructive sleep apnoea.

included in the final quantitative analysis. The mean age was 62 years and $64 \%$ were men. The median study methodological quality score was 9 (7-9) (online supplemental table 3).

\section{The risk of all-cause sudden death associated with OSA}

The RR point estimates for all-cause sudden death associated with OSA ranged from 0.80 to 9.20 (figure 2). The pooled RR of sudden death associated with OSA was 1.74 (95\% CI: 1.4 to 2.10), implying an approximately twofold higher risk of death. Between-study heterogeneity was moderate $\left(\mathrm{I}^{2}=72 \%\right)$. We calculated the dose-response relation between severity OSA and all-cause sudden death. There was a marginally significant dose-response relationship between OSA and all-cause sudden death ( $\mathrm{p}$ for interaction $=0.05$ ). The RR for mild OSA was 1.16 (95\% CI: 0.70 to $1.93, \mathrm{I}^{2}=66 \%$ ), for moderate OSA was $1.72\left(95 \%\right.$ CI: 1.11 to $2.67, \mathrm{I}^{2}=0 \%$ ) and severe OSA was 2.87 (95\% CI: 1.70 to $4.85, \mathrm{I}^{2}=0 \%$ ) (figure 3 ).

\section{The risk of cardiovascular mortality associated with OSA}

The point estimates of cardiovascular mortality ranged from 0.80 to 4.19 (figure 4). Overall, individuals with OSA had a nearly twofold higher risk of cardiovascular mortality than those without OSA ( $R R=1.94,95 \%$ CI 1.39 to $2.70, \mathrm{I}^{2}=32 \%$ ).
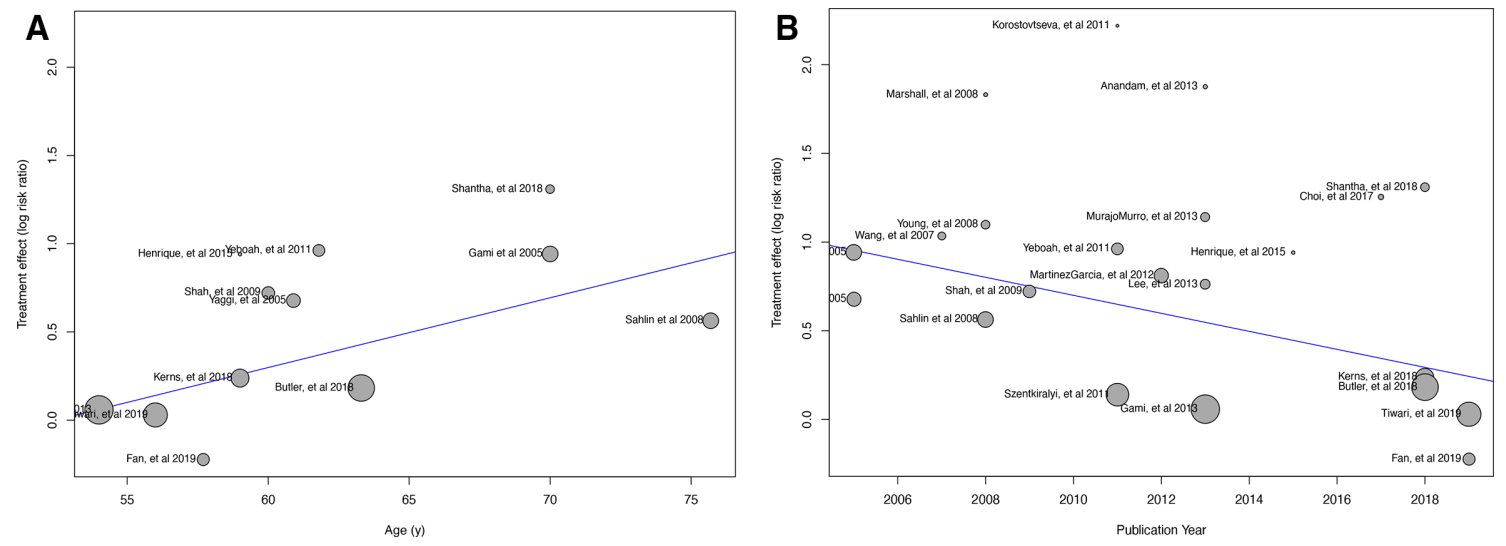

Figure 7 Univariate meta-regression analysis. Meta-regression bubble plots using age $(A)$ and the publication year $(B)$ as covariates.

\section{Subgroup and meta-regression analyses}

The study heterogeneity for the association of OSA and all-cause sudden death was moderate $\left(\mathrm{I}^{2}=72 \%\right)$. Therefore, we explored sources of heterogeneity by conducting subgroup analysis with study quality scores and the continent of the study population as covariates. Studies with a score of 9 were compared with those with a score of $<9$. In the studies with high-quality score, the relationship between OSA and mortality was significant ( $R R=1.91$, 95\% CI: 1.50 to $2.44, \mathrm{I}^{2}=64 \%$ ) but not in the studies with a moderate quality score ( $\mathrm{RR}=1.52,95 \% \mathrm{CI}: 0.97$ to 2.37 , $\mathrm{I}^{2}=79 \%$ ) (figure 5). The test for the subgroup differences was not significant $(p=0.37)$.

Subgroup analysis by continents showed significant pooled RRs for North America, Europe and Australia. However, the pooled RRs for Asia and South America were not significant (figure 6). The test for the subgroup differences was not significant $(\mathrm{p}=0.47)$.

Furthermore, we conducted univariate metaregression with mean or median study age, publication year, the proportion of participants with diabetes and male proportion as covariates. ${ }^{48}$ Meta-regression results revealed that year of publication and mean age significantly explained the variations in the pooled estimates (table 1, figure 7). On the other hand, no statistically significant effects from sex or diabetes covariates were observed. 


\section{Publication bias and influence analysis}

We explored publication and small study bias with funnel plots and Egger's test. We found the publication bias to be significant, as evidenced by asymmetrical funnel plot and significant Egger's test $(\mathrm{p}<0.0001)$ (online supplemental figure 1). To adjust for the publication bias, the trim and fill method was conducted. ${ }^{20}$ Our analyses showed that if the asymmetry is due to publication bias, the adjusted effect estimates for OSA and sudden death remained significant ( $\mathrm{RR}=1.23,95 \% \mathrm{CI}$ : 1.02 to 1.50 , $\mathrm{p}=0.03$ ) (online supplemental figure 2). Finally, influence sensitivity analyses did not indicate outlier studies ${ }^{17}$ (online supplemental figure 3).

\section{DISCUSSION}

The results of the present systematic review and meta-analysis suggest that individuals with OSA have a greater risk of allcause sudden and cardiovascular death. The risk increases with age.

The twofold higher risk of deaths associated with OSA was similar to the effect estimates by Fonseca and colleagues who summarised studies published between 2002 and 2014 and included 13394 participants from 13 studies. $^{49}$ There is a large amount of evidence in research that supports the notion that OSA is associated with numerous cardiovascular conditions, including hypertension, coronary artery disease, congestive heart failure, arrhythmias and more. ${ }^{50}$ This association may be explained by the influence that the nervous system has on the sleep cycle in humans. OSA results in intermittent hypoxia and oxygen desaturation during sleep, which may cause over-arousal of the central nervous system to increase airflow. The complex relationship between the sympathetic nervous system and the autonomic nervous system causes a transient increase in both systolic and diastolic blood pressure during apnoeas. ${ }^{51}{ }^{52}$ Acute sympathetic activation during sleep and sustained elevation in sympathetic activity while awake and are important mechanisms of cardiovascular morbidity and mortality in patients with OSA. ${ }^{53-55}$

Furthermore, individuals with OSA experience sustained oxidative stress. OSA is associated with a group of proinflammatory and prothrombotic factors that are important in the development of atherosclerosis. ${ }^{56} \mathrm{C}$ reactive protein, an inflammatory marker of oxidative stress, is increased in OSA patients and is associated with endothelial dysfunction. ${ }^{57}$ Also, Advanced glycation endproducts are increased in non-diabetic subjects with OSA and are associated with the severity of OSA. ${ }^{58}$ Lastly, fibrinogen, plasminogen activator inhibitor and reduced fibrinolytic activity in OSA is associated with enhanced platelet activity and aggregation, endothelial cells leucocyte adhesion and accumulation leading to atherosclerosis and myocardial infarction. ${ }^{56}$

Our study had some limitations. First, although we gave priority to adjusted RR, it isplausible that residual confounding persisted in the estimates provided by each study. Therefore, our results should be interpreted with caution. Second, we combined adjusted and unadjusted $\mathrm{RR}$ in calculating pooled estimates. It is possible that such a method could have introduced the medium between-study heterogeneity we observed. Nevertheless, we used robust statistical models to explore covariates responsible for the observed variations. Indeed, we found age, study quality, publication year and the continent of the study population to significantly impact the variation of the pooled estimates. Lastly, although this meta-analysis included studies representative of five continents, including North America, Australia, Europe, Asia and South America, we were unable to identify any studies from Africa. Thus, these findings may not be generalisable in the African setting. There is a need for further research to confirm if the association between OSA and mortality remains true in populations not represented in our meta-analysis.

\section{CONCLUSION}

Individuals with OSA have nearly a twofold higher risk of sudden death and cardiovascular mortality. Treatments and interventions related to decreasing this risk and other adverse outcomes are necessary to optimise survival and QOL.

Contributors AES, PS, ESH and VMC conceived the study. AES, ESH and PS conducted the literature search. AES and PS completed data analysis. AES, ESH, PS, VMC and JO interpreted the data. AES, ESH and PS wrote the manuscript. All authors agreed to the manuscript in its final form.

Funding The authors have not declared a specific grant for this research from any funding agency in the public, commercial or not-for-profit sectors.

Competing interests None declared.

Patient consent for publication Not required.

Ethics approval This is a systematic review and meta-analysis, and individual patient was not used. Therefore, we did not need IRB or an ethics board approval.

Provenance and peer review Not commissioned; externally peer reviewed.

Data availability statement All data relevant to the study are included in the article or uploaded as supplementary information.

Supplemental material This content has been supplied by the author(s). It has not been vetted by BMJ Publishing Group Limited (BMJ) and may not have been peer-reviewed. Any opinions or recommendations discussed are solely those of the author(s) and are not endorsed by BMJ. BMJ disclaims all liability and responsibility arising from any reliance placed on the content. Where the content includes any translated material, BMJ does not warrant the accuracy and reliability of the translations (including but not limited to local regulations, clinical guidelines, terminology, drug names and drug dosages), and is not responsible for any error and/or omissions arising from translation and adaptation or otherwise.

Open access This is an open access article distributed in accordance with the Creative Commons Attribution Non Commercial (CC BY-NC 4.0) license, which permits others to distribute, remix, adapt, build upon this work non-commercially, and license their derivative works on different terms, provided the original work is properly cited, appropriate credit is given, any changes made indicated, and the use is non-commercial. See: http://creativecommons.org/licenses/by-nc/4.0/.

ORCID iD

Anna E Ssentongo http://orcid.org/0000-0001-9104-1323

\section{REFERENCES}

1 Arnold J, Sunilkumar M, Krishna V, et al. Obstructive sleep apnea. J Pharm Bioallied Sci 2017;9:26-8.

2 Osman AM, Carter SG, Carberry JC, et al. Obstructive sleep apnea: current perspectives. Nat Sci Sleep 2018;10:21-34.

3 Bonsignore MR, Baiamonte P, Mazzuca E, et al. Obstructive sleep apnea and comorbidities: a dangerous liaison. Multidiscip Respir Med 2019;14:8. 
4 Motamedi KK, McClary AC, Amedee RG. Obstructive sleep apnea: a growing problem. Ochsner J 2009;9:149-53.

5 Jean-Louis G, Zizi F, Clark LT, et al. Obstructive sleep apnea and cardiovascular disease: role of the metabolic syndrome and its components. J Clin Sleep Med 2008;4:261-72.

6 Yaggi HK, Concato J, Kernan WN, et al. Obstructive sleep apnea as a risk factor for stroke and death. N Engl J Med 2005;353:2034-41.

7 Marshall NS, Wong KKH, Cullen SRJ, et al. Sleep apnea and 20-year follow-up for all-cause mortality, stroke, and cancer incidence and mortality in the Busselton health study cohort. J Clin Sleep Med 2014;10:355-62.

8 Benjafield AV, Ayas NT, Eastwood PR, et al. Estimation of the global prevalence and burden of obstructive sleep apnoea: a literaturebased analysis. Lancet Respir Med 2019;7:687-98.

9 Young T, Palta M, Dempsey J, et al. Burden of sleep apnea: rationale, design, and major findings of the Wisconsin sleep cohort study. WMJ 2009;108:246-9.

10 Tarasiuk A, Reuveni H. The economic impact of obstructive sleep apnea. Curr Opin Pulm Med 2013;19:639-44.

11 Heilbrunn E, Ssentongo P, Chinchilli VM, et al. Sudden death in individuals with obstructive sleep apnoea: protocol for a systematic review and meta-analysis. BMJ Open 2020;10:e039774.

12 Balduzzi S, Rücker G, Schwarzer G. How to perform a meta-analysis with R: a practical tutorial. Evid Based Ment Health 2019;22:153-60.

13 DerSimonian R, Kacker R. Random-effects model for meta-analysis of clinical trials: an update. Contemp Clin Trials 2007;28:105-14.

14 Greenland S. Quantitative methods in the review of epidemiologic literature. Epidemiol Rev 1987;9:1-30.

15 Higgins JPT, Thompson SG. Quantifying heterogeneity in a metaanalysis. Stat Med 2002;21:1539-58.

16 Higgins JPT, Thompson SG, Deeks JJ, et al. Measuring inconsistency in meta-analyses. BMJ 2003;327:557-60.

17 Viechtbauer W, Cheung MW-L. Outlier and influence diagnostics for meta-analysis. Res Synth Methods 2010;1:112-25.

18 Schwarzer G, Carpenter JR, Rücker G. Meta-Analysis with R. Springer, 2015.

19 Egger M, Davey Smith G, Schneider M, et al. Bias in meta-analysis detected by a simple, graphical test. BMJ 1997;315:629-34.

20 Duval S, Tweedie R. Trim and fill: a simple funnel-plot-based method of testing and adjusting for publication bias in meta-analysis. Biometrics 2000;56:455-63.

21 Team RC. $R$ core team (2017). R: a language and environment for statistical computing. $R$ found STAT Comput. Vienna, Austria: R Foundation for Statistical Computing, 2017. http://www R-project org/

22 Kerns ES, Kim ED, Meoni LA, et al. Obstructive sleep apnea increases sudden cardiac death in incident hemodialysis patients. Am J Nephrol 2018;48:147-56.

23 Zhang M, Li L, Fowler D, et al. Causes of sudden death in patients with obstructive sleep apnea. J Forensic Sci 2013;58:1171-4.

24 Gami AS, Olson EJ, Shen WK, et al. Obstructive sleep apnea and the risk of sudden cardiac death: a longitudinal study of 10,701 adults. $J$ Am Coll Cardiol 2013;62:610-6.

25 Martins EF, Martinez D, da Silva FABS, et al. Disrupted day-night pattern of cardiovascular death in obstructive sleep apnea. Sleep Med 2017:38:144-50.

26 Szentkiralyi A, Czira ME, Molnar MZ, et al. High risk of obstructive sleep apnea is a risk factor of death censored graft loss in kidney transplant recipients: an observational cohort study. Sleep Med 2011;12:267-73.

27 Shah NA, Yaggi HK, Concato J, et al. Obstructive sleep apnea as a risk factor for coronary events or cardiovascular death. Sleep Breath 2010;14:131-6.

28 Sahlin C, Sandberg O, Gustafson Y, et al. Obstructive sleep apnea is a risk factor for death in patients with stroke: a 10-year follow-up. Arch Intern Med 2008;168:297-301.

29 Cassar A, Morgenthaler TI, Lennon RJ, et al. Treatment of obstructive sleep apnea is associated with decreased cardiac death after percutaneous coronary intervention. J Am Coll Cardiol 2007;50:1310-4.

30 Gami AS, Howard DE, Olson EJ, et al. Day-Night pattern of sudden death in obstructive sleep apnea. N Engl J Med 2005;352:1206-14.

31 Rössner S, Lagerstrand L, Persson HE, et al. The sleep apnoea syndrome in obesity: risk of sudden death. $J$ Intern Med 1991;230:135-41.

32 Tiwari R, Lyu B, Alagusundaramoorthy S, et al. Association of diagnosed obstructive sleep apnea with kidney transplant outcomes. Clin Transplant 2019;33. doi:10.1111/ctr.13747. [Epub ahead of print: 26 Nov 2019].
33 Sweed RA, Hassan S, ElWahab NHA, et al. Comorbidities associated with obstructive sleep apnea: a retrospective Egyptian study on 244 patients. Sleep Breath 2019;23:1079-85.

34 Butler MP, Emch JT, Rueschman M, et al. Apnea-Hypopnea event duration predicts mortality in men and women in the sleep heart health study. Am J Respir Crit Care Med 2019;199:903-12.

35 Fan J, Wang X, Ma X, et al. Association of obstructive sleep apnea with cardiovascular outcomes in patients with acute coronary syndrome. J Am Heart Assoc 2019;8:e010826.

36 Shantha G, Mentias A, Pothineni NVK, et al. Role of obstructive sleep apnea on the response to cardiac resynchronization therapy and all-cause mortality. Heart Rhythm 2018;15:1283-8.

37 Jennum P, Baandrup L, Tønnesen P, et al. Mortality and use of psychotropic medication in sleep apnoea patients: a populationwide register-based study. Sleep Med 2018;43:19-24.

38 Lee J-E, Lee CH, Lee SJ, et al. Mortality of patients with obstructive sleep apnea in Korea. J Clin Sleep Med 2013;9:997-1002.

39 Yeboah J, Redline S, Johnson C, et al. Association between sleep apnea, snoring, incident cardiovascular events and allcause mortality in an adult population: MESA. Atherosclerosis 2011;219:963-8.

40 Uchôa CHG, Danzi-Soares NdeJ, Nunes FS, et al. Impact of OSA on cardiovascular events after coronary artery bypass surgery. Chest 2015;147:1352-60.

41 Anandam A, Patil M, Akinnusi M, et al. Cardiovascular mortality in obstructive sleep apnoea treated with continuous positive airway pressure or oral appliance: an observational study. Respirology 2013;18:1184-90.

42 Choi J-W, Song JS, Lee YJ, et al. Increased mortality in relation to insomnia and obstructive sleep apnea in Korean patients studied with nocturnal polysomnography. J Clin Sleep Med 2017;13:49-56.

43 Korostovtseva LS, Sviryaev YV, Zvartau NE, et al. Prognosis and cardiovascular morbidity and mortality in prospective study of hypertensive patients with obstructive sleep apnea syndrome in ST Petersburg, Russia. Med Sci Monit 2011;17:CR146-53.

44 Wang H, Parker JD, Newton GE, et al. Influence of obstructive sleep apnea on mortality in patients with heart failure. J Am Coll Cardiol 2007;49:1625-31.

45 Young T, Finn L, Peppard PE, et al. Sleep disordered breathing and mortality: eighteen-year follow-up of the Wisconsin sleep cohort. Sleep 2008;31:1071-8.

46 Martínez-García M-A, Campos-Rodríguez F, Catalán-Serra P, et al. Cardiovascular mortality in obstructive sleep apnea in the elderly: role of long-term continuous positive airway pressure treatment: a prospective observational study. Am J Respir Crit Care Med 2012;186:909-16.

47 Muraja-Murro A, Eskola K, Kolari T, et al. Mortality in middleaged men with obstructive sleep apnea in Finland. Sleep Breath 2013;17:1047-53.

48 Borenstein M, Hedges LV, Higgins JP. Introduction to meta-analysis. John Wiley \& Sons, 2011.

49 Fonseca MIP, Pereira T, Caseiro P. Death and disability in patients with sleep apnea--a meta-analysis. Arq Bras Cardiol 2015;104:58-66.

50 Lee W, Nagubadi S, Kryger MH, et al. Epidemiology of obstructive sleep apnea: a population-based perspective. Expert Rev Respir Med 2008:2:349-64.

51 Bisogni V, Pengo MF, Maiolino G, et al. The sympathetic nervous system and catecholamines metabolism in obstructive sleep apnoea. J Thorac Dis 2016;8:243-54.

52 Brodovskaya TO, Grishina IF, Peretolchina TF, et al. Clues to the pathophysiology of sudden cardiac death in obstructive sleep apnea. Cardiology 2018;140:247-53.

53 Shamsuzzaman AS, Somers VK, Knilans TK, et al. Obstructive sleep apnea in patients with congenital long QT syndrome: implications for increased risk of sudden cardiac death. Sleep 2015;38:1113-9.

54 Somers VK, Dyken ME, Clary MP, et al. Sympathetic neural mechanisms in obstructive sleep apnea. $J$ Clin Invest 1995;96:1897-904.

55 Narkiewicz K, Somers VK. Sympathetic nerve activity in obstructive sleep apnoea. Acta Physiol Scand 2003;177:385-90.

56 Kasasbeh E, Chi DS, Krishnaswamy G. Inflammatory aspects of sleep apnea and their cardiovascular consequences. South Med J 2006;99:58-67.

57 Volná J, Kemlink D, Kalousová M, et al. Biochemical oxidative stress-related markers in patients with obstructive sleep apnea. Med Sci Monit 2011;17:CR491

58 Tan KCB, Chow W-S, Lam JCM, et al. Advanced glycation endproducts in nondiabetic patients with obstructive sleep apnea. Sleep 2006;29:329-33. 